\title{
Statistical properties of Odd Frèchet Lomax Distribution
}

\author{
Sanaa Al-Marzouki \\ Statistics Department, Faculty of Science, King AbdulAziz University, Jeddah, Kingdom of Saudi Arabia \\ E-mail : salmarzouki@kau.edu.sa
}

\begin{abstract}
A new lifetime distribution with three parameters, called odd Frèchet Lomax (OFrL), is introduced. Some statistical properties of the OFrL are provided. Explicit expressions for the quntile, moments, moment generating function, probability weighted moments and order statistics are studied. Maximum likelihood estimation technique is employed to estimate the model parameters are studied. In addition, the superiority of the OFrL distribution is illustrated with applications to one real data set.
\end{abstract}

Keywords: Odd Frèchet -G family; Lomax distribution, Order statistics; moments.

DOI: $10.7176 / \mathrm{MTM} / 9-1-08$

\section{Introduction}

Lomax (1954) introduced The Lomax (L) distribution. The L distribution has found wide applications such as the analysis of the business failure life time data, income and wealth inequality, medical and biological sciences, engineering, lifetime and reliability modeling. The $\mathrm{L}$ distribution is used for reliability modelling and life testing by Hassan and Al-Ghamdi (2009). Corbelini et al. (2007) proposed it to model firm size and queuing problems.

Many researchers introduced several generalizations of the L distribution. Ghitany et al. (2007) investigated the Marshal-Olkin extended L distribution, Abdul-Moniem and Abdel-Hameed (2012) introduced the exponentiated L distribution, Lemonte and Cordeiro (2013) proposed the McDonald L, Cordeiro et al. (2013) investigated the gamma L distribution. The exponential L distribution is studied by ElBassiouny et al. (2015). Al-Weighted L introduced by Kilany (2016), and Tahir et al. (2015) introduced Weibull L distribution. The L distribution it has the following cumulative distribution function (cdf) and probability density function (pdf) as

$$
G(x)=1-\left(1+\frac{x}{\lambda}\right)^{-\alpha} \quad x>0, \alpha, \lambda>0,
$$

and

$$
g(x)=\frac{\alpha}{\lambda}\left(1+\frac{x}{\lambda}\right)^{-\alpha-1} \quad x>0, \alpha, \lambda>0
$$

Where $\alpha$ is a shape parameters and $\lambda$ is a scale parameter.

Recently, Haq and Elgarhy (2018) studied odd Frèchet generated (OF-G) family of distributions. The cdf of $O F-G$ is given by:

$$
F(x: \theta, \xi)=\int_{0}^{\left[\frac{G(x ; \xi)}{1-G(x ; \xi)}\right]} \frac{\theta}{x^{\theta+1}} e^{-x^{-\theta}} d x=e^{-\left[\frac{1-G(x ; \xi)}{G(x ; \xi)}\right]^{\theta}} \quad, x \in R, \theta>0 .
$$

The corresponding pdf to (3) is given by

$$
f(x: \theta, \xi)=\frac{\theta g(x ; \xi)[1-G(x ; \xi)]^{\theta-1}}{G(x ; \xi)^{\theta+1}} e^{-\left[\frac{1-G(x ; \xi)}{G(x ; \xi)}\right]^{\theta}}
$$

where $g(x: \xi)$ considers a pdf of baseline distribution. Hereafter, a random variable $X$ with density function (4) is denoted by $X \sim O F-G(\theta, \xi)$.

The rest of the paper is arranged as follows: In Section 2, we define the OFrL distribution. In Section 3, we derive a very useful expansion for the OFrL density and distribution functions. Further, we derive some 
mathematical properties of the new distribution. The maximum likelihood (ML) method is used to estimate the model parameters in Section 4. Simulation study is carried out to estimate the model parameters of OFrL distribution in Section 5. In Section 6, we using one real data set to show the importance of the OFrL distribution. Finally, summary in Section 7.

\section{The OFrL distribution}

In this section,we introduce the new three-parameter OFrL distribution, the cdf and pdf of the OFrL distribution is given by

$$
F(x ; \theta, \alpha, \lambda)=e^{-\left[\left(1+\frac{x}{\lambda}\right)^{\alpha}-1\right]^{-\theta}}, x>0, \theta, \alpha, \lambda>0
$$

and

$$
f(x)=\frac{\alpha \theta}{\lambda}\left(1+\frac{x}{\lambda}\right)^{\alpha-1}\left[\left(1+\frac{x}{\lambda}\right)^{\alpha}-1\right]^{-\theta-1} e^{-\left[\left(1+\frac{x}{\lambda}\right)^{\alpha}-1\right]^{-\theta}}, \quad x, \theta, \alpha, \lambda>0
$$

Where $\lambda$ is scale parameter and $\alpha, \theta$ are two shape parameters.

Figure 1 displays some plots of the pdf for the $O F r L$ pdf for some different values of parameters.

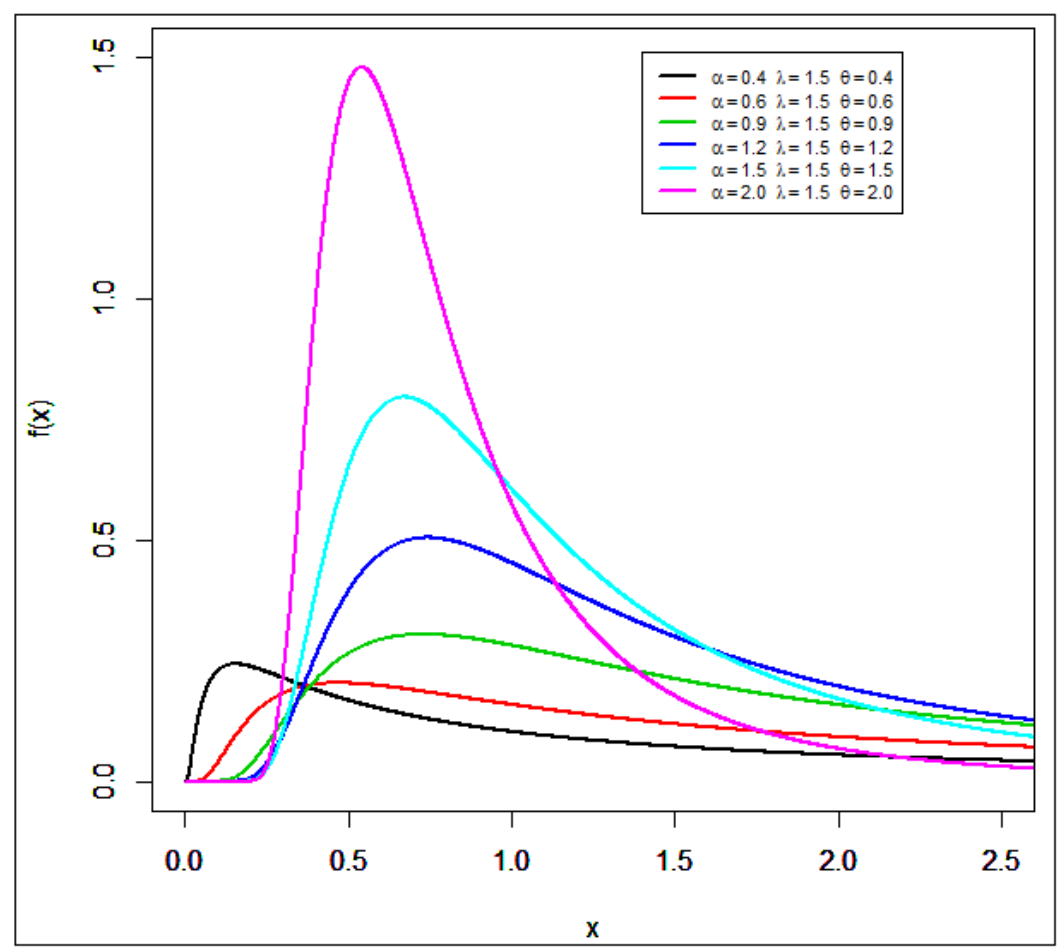

Figure 1: Plots of the pdf for OFrL distribution for different values of parameters

From Figure 1, we conclude that pdf of OFrL distribution can be unimodal and right skewed.

The survival function (sf), hazard rate function (hrf), reversed hrf and cumulative hrf of $X$ are given, respectively, as follows:

$$
\begin{gathered}
R(x)=1-e^{-\left[\left(1+\frac{x}{\lambda}\right)^{\alpha}-1\right]^{-\theta}}, \\
h(x)=\frac{\frac{\alpha \theta}{\lambda}\left(1+\frac{x}{\lambda}\right)^{\alpha-1}\left[\left(1+\frac{x}{\lambda}\right)^{\alpha}-1\right]^{-\theta-1} e^{-\left[\left(1+\frac{x}{\lambda}\right)^{\alpha}-1\right]^{-\theta}}}{1-e^{-\left[\left(1+\frac{x}{\lambda}\right)^{\alpha}-1\right]^{-\theta}}},
\end{gathered}
$$




$$
\tau(x)=\frac{\alpha \theta}{\lambda}\left(1+\frac{x}{\lambda}\right)^{\alpha-1}\left[\left(1+\frac{x}{\lambda}\right)^{\alpha}-1\right]^{-\theta-1}
$$

and

$$
H(x)=-\ln \left(1-e^{-\left[\left(1+\frac{x}{\lambda}\right)^{\alpha}-1\right]^{-\theta}}\right)
$$

Figure 2 displays some plots of the hrf for the OFrL for some different values of parameters.

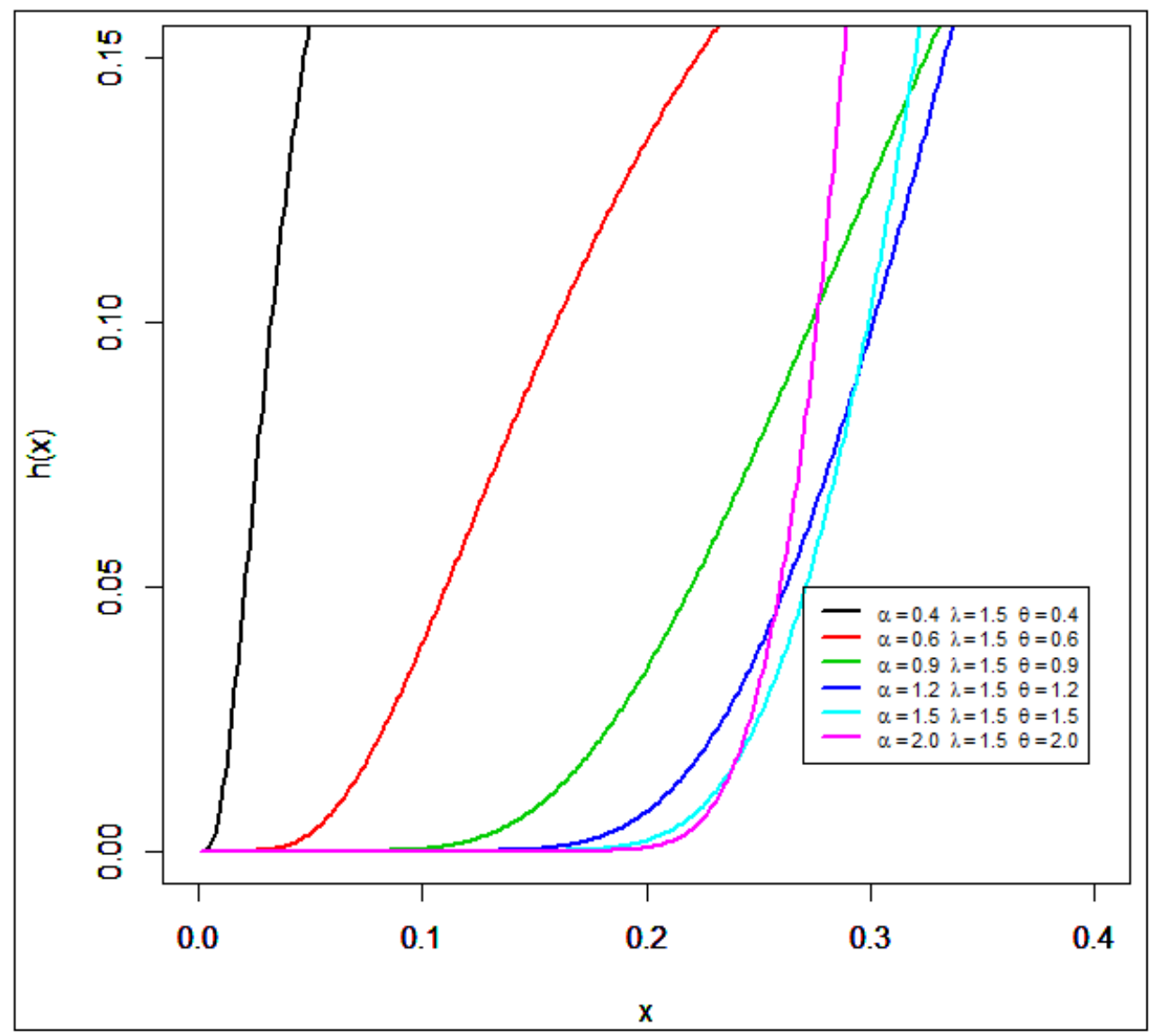

Figure 2: Plots of the hrf for OFrL distribution for different values of parameters From Figure 2, we conclude that the hrf of OFrL distribution can be J- shaped and increasing.

\section{Fundamental properties}

In this section, we study some fundamental statistical properties for OFrL distribution.

\subsection{Useful expansions}

In this section expansion of the pdf for $O F r L$ distribution are calculated.

Haq and Elgarhy (2018) expressed the equation (6) as

$$
f(x)=\sum_{k=0}^{\infty} \eta_{k} g(x, \xi) G(x, \xi)^{k}
$$

where

$$
\eta_{k}=\sum_{i, j=0}^{\infty} \frac{\theta(-1)^{i+k}}{i !}\left(\begin{array}{c}
\theta(i+1)+j \\
j
\end{array}\right)\left(\begin{array}{c}
\theta(i+1)+j-1 \\
k
\end{array}\right)
$$


By inserting (6) in (7) we can rewite the $O F r L$ as a linear combination of $P L$ distribution as

$$
f(x)=\sum_{k=0}^{\infty} \eta_{k} \frac{\alpha}{\lambda}\left(1+\frac{x}{\lambda}\right)^{-\alpha-1}\left(1-\left(1+\frac{x}{\lambda}\right)^{-\alpha}\right)^{k},
$$

now, consider the following well-known binomial expansions (for $0<\mathrm{a}<1$ ),

$$
(1-a)^{n}=\sum_{m=0}^{\infty}(-1)^{m}\left(\begin{array}{c}
a \\
m
\end{array}\right) a^{m} .
$$

Thus, using (9), the following term in (8) can be expressed as

$$
\left(1-\left(1+\frac{x}{\lambda}\right)^{-\alpha}\right)^{k}=\sum_{m=0}^{\infty}(-1)^{m}\left(\begin{array}{c}
k \\
m
\end{array}\right)\left(1+\frac{x}{\lambda}\right)^{-\alpha m} .
$$

Therefore, from (10) and (8) the pdf of OFrL can be write as

Where $w_{m}=\sum_{k=0}^{\infty} \alpha \eta_{k}(-1)^{m}\left(\begin{array}{c}k \\ m\end{array}\right)$.

$$
f(x)=\frac{1}{\lambda} \sum_{m=0}^{\infty} w_{m}\left(1+\frac{x}{\lambda}\right)^{-\alpha(m+1)-1}
$$

\subsection{Quantile and Median}

The quantile function, say $Q(u)=F^{-1}(u)$ of $\mathrm{X}$ is given by

$$
Q(u)=\lambda\left(1+\left(\ln \left(\frac{1}{u}\right)\right)^{\frac{-1}{\theta}}\right)^{\frac{1}{\alpha}}-\lambda .
$$

Where, $u$ is considered as a uniform random variable on the unit interval $(0,1)$.

The median can be calculated by setting $u=0.5$ in (7). Then, the median (M) is given by

\subsection{Moments}

$$
M=\lambda\left(1+(\ln (2))^{\frac{-1}{\theta}}\right)^{\frac{1}{\alpha}}-\lambda
$$

In this subsection, we intend to derive the moments and the moment generating function of the OFrL model.

If $\mathrm{X}$ has the pdf (11), then its $r$ th moment is given by

$$
\mu_{r}^{\prime}=\int_{0}^{\infty} x^{r} f(x) d x .
$$

By inserting (11) into (12), we get

$$
\mu_{r}^{\prime}=\frac{1}{\lambda} \sum_{m=0}^{\infty} w_{m} \int_{0}^{\infty} x^{r}\left(1+\frac{x}{\lambda}\right)^{-\alpha(m+1)-1} d x .
$$

Let $y=\frac{x}{\lambda}$, then,

$$
\mu_{r}^{\prime}=\sum_{m=0}^{\infty} w_{m} \lambda^{r} \int_{0}^{\infty} y^{r}(1+y)^{-\alpha(m+1)-1} d y .
$$

Again make the following transformation $y=\frac{w}{1-w}$

$$
\mu_{r}^{\prime}=\sum_{m=0}^{\infty} w_{m} \lambda^{r} \int_{0}^{1} w^{r}(1-w)^{\alpha(m+1)-r-1} d w
$$


Hence, the $r$ th moment of OFrL distribution takes the following form

$$
\tau_{r, s}=\sum_{m=0}^{\infty} w_{m} \lambda^{r} B[r+1, \alpha(m+1)-r] \text {. }
$$

The moment generating function (mgf) of the OFrL distribution is

$$
M_{x}(t)=E\left(e^{t X}\right)=\int_{0}^{\infty} e^{t x} f(x) d x=\sum_{r=0}^{\infty} \frac{t^{r}}{r !} E\left(X^{r}\right)
$$

then,

$$
M_{x}(t)=\sum_{r, m=0}^{\infty} \frac{t^{r}}{r !} w_{m} \lambda^{r} B[r+1, \alpha(m+1)-r]
$$

\subsection{Order Statistics}

Let $X_{1: n}<X_{2: n}<\ldots<X_{n: n}$ be the order statistics of a random sample of size $n$ following the $O F r L$ distribution, with parameters $\alpha, \lambda$ and $\theta$, then, the pdf of the $k$ th order statistic, can be written as follows

$$
f_{k: n}(x)=\frac{1}{B(k, n-k+1)} f(x) F(x)^{k-1}(1-F(x))^{n-k},
$$

where, $B(.,$.$) is the beta function. By substituting (5) and (6) in (13), then$

$$
\begin{gathered}
f_{k: n}(x)=\frac{\theta \alpha}{\lambda B(k, n-k-1)}\left(1+\frac{x}{\lambda}\right)^{\alpha-1}\left[\left(1+\frac{x}{\lambda}\right)^{\alpha}-1\right]^{-\theta-1} e^{-\mathrm{k}\left[\left(1+\frac{x}{\lambda}\right)^{\alpha}-1\right]^{-\theta}} \\
\left(1-e^{-\left[\left(1+\frac{x}{\lambda}\right)^{\alpha}-1\right]^{-\theta}}\right)^{n-k}
\end{gathered}
$$

When we put $k=1$ in (14) we get the pdf of the smallest order statistics as

$$
f_{1: n}(x)=\frac{n \theta \alpha}{\lambda}\left(1+\frac{x}{\lambda}\right)^{\alpha-1}\left[\left(1+\frac{x}{\lambda}\right)^{\alpha}-1\right]^{-\theta-1} e^{-\left[\left(1+\frac{x}{\lambda}\right)^{\alpha}-1\right]^{-\theta}}\left(1-e^{-\left[\left(1+\frac{x}{\lambda}\right)^{\alpha}-1\right]^{-\theta}}\right)^{n-1}
$$

when we put $k=n$ in (14) we get the pdf of the largest order statistics as

$$
f_{n: n}(x)=\frac{n \theta \alpha}{\lambda}\left(1+\frac{x}{\lambda}\right)^{\alpha-1}\left[\left(1+\frac{x}{\lambda}\right)^{\alpha}-1\right]^{-\theta-1} e^{-\mathrm{k}\left[\left(1+\frac{x}{\lambda}\right)^{\alpha}-1\right]^{-\theta}} .
$$

\section{ML Estimation}

The ML estimates of the unknown parameters for the OFrL distribution are determined based on complete samples. Let $X_{1}, \ldots, X_{n}$ be observed values from the OFrL model with set of parameters $\varphi=(\alpha, \lambda, \theta)^{T}$. The total loglikelihood function for the vector of parameters $\varphi$ can be expressed as

$\ln L(\varphi)=n \ln \alpha-n \ln \lambda+n \ln \theta+(\alpha-1) \sum_{i=1}^{n} \ln \left(1+\frac{x_{i}}{\lambda}\right)-(\theta+1) \sum_{i=1}^{n} \ln \left(\left(1+\frac{x_{i}}{\lambda}\right)^{\alpha}-1\right)-\sum_{i=1}^{n}\left(\left(1+\frac{x_{i}}{\lambda}\right)^{\alpha}-1\right)^{-\theta}$

The elements of the score function $U(\varphi)=\left(U_{\alpha}, U_{\lambda}, U_{\theta}\right)$ are given by 


$$
\begin{gathered}
U_{\alpha}=\frac{n}{\alpha}+\sum_{i=1}^{n} \ln \left(1+\frac{x_{i}}{\lambda}\right)-(\theta+1) \sum_{i=1}^{n} \frac{\left(1+\frac{x_{i}}{\lambda}\right)^{\alpha} \ln \left(1+\frac{x_{i}}{\lambda}\right)}{\left(1+\frac{x_{i}}{\lambda}\right)^{\alpha}-1} \\
+\theta \sum_{i=1}^{n}\left(\left(1+\frac{x_{i}}{\lambda}\right)^{\alpha}-1\right)^{-\theta-1}\left(1+\frac{x_{i}}{\lambda}\right)^{\alpha} \ln \left(1+\frac{x_{i}}{\lambda}\right), \\
U_{\lambda}=\frac{-n}{\lambda}-(\alpha-1) \sum_{i=1}^{n}\left(\frac{\lambda^{-2} x_{i}}{1+\frac{x_{i}}{\lambda}}\right)^{+}+(\theta+1) \alpha \sum_{i=1}^{n} \frac{\lambda^{-2} x_{i}\left(1+\frac{x_{i}}{\lambda}\right)^{\alpha-1}}{\left(1+\frac{x_{i}}{\lambda}\right)^{\alpha}-1} \\
-\theta \alpha \sum_{i=1}^{n} \lambda^{-2} x_{i}\left(\left(1+\frac{x_{i}}{\lambda}\right)^{\alpha}-1\right)^{-\theta-1}\left(1+\frac{x_{i}}{\lambda}\right)^{\alpha-1},
\end{gathered}
$$

and

$$
U_{\theta}=\frac{n}{\theta}-\sum_{i=1}^{n} \ln \left(\left(1+\frac{x_{i}}{\lambda}\right)^{\alpha}-1\right)+\sum_{i=1}^{n}\left(\left(1+\frac{x_{i}}{\lambda}\right)^{\alpha}-1\right)^{-\theta} \ln \left(\left(1+\frac{x_{i}}{\lambda}\right)^{\alpha}-1\right)
$$

Then the ML estimators of the parameters $\alpha, \lambda$ and $\theta$ are obtained by setting $U_{\alpha}, U_{\lambda}$ and $U_{\theta}$ to be zero and solving them. Clearly, it is difficult to solve them, therefore applying the Newton-Raphson's iteration method and using the computer package such as Maple or R or other software.

\section{Simulation Study}

It is very difficult to compare the theoretical performances of the different estimators (MLE) for the OFrL distribution. A numerical study is performed using Mathematica 9 software. Different sample sizes are considered through the experiments at size $n=30,50$ and 100. In addition, the different values of parameters $\alpha, \lambda$ and $\theta$.

The experiment will be repeated 3000 times. In each experiment, the estimates of the parameters will be obtained by ML methods of estimation. The means, MSEs and biases for the different estimators will be reported from these experiments.

Table (1): The parameter estimation for OFrL distribution using MLE

\begin{tabular}{|c|c|c|c|c|c|c|c|}
\hline \multirow{2}{*}{$n$} & \multirow{2}{*}{ Par } & \multicolumn{3}{|c|}{ Set 1: $(0.5,0.5,0.5)$} & \multicolumn{3}{c|}{ Set $2:(0.5,0.5,0.8)$} \\
\cline { 3 - 8 } & & MLE & Bais & MSE & MLE & Bais & MSE \\
\hline \multirow{3}{*}{30} & $\alpha$ & 0.5203 & 0.0203 & 0.0091 & 0.5242 & 0.0241 & 0.0242 \\
\cline { 2 - 8 } & $\lambda$ & 0.5058 & 0.0058 & 0.0019 & 0.5063 & 0.0063 & 0.0052 \\
\cline { 2 - 8 } & $\theta$ & 0.5297 & 0.0297 & 0.0196 & 0.8536 & 0.0536 & 0.0591 \\
\hline \multirow{3}{*}{50} & $\alpha$ & 0.5062 & 0.0062 & 0.0050 & 0.5185 & 0.0185 & 0.0103 \\
\cline { 2 - 8 } & $\lambda$ & 0.5012 & 0.0012 & 0.0009 & 0.5059 & 0.0059 & 0.0026 \\
\cline { 2 - 8 } & $\theta$ & 0.5139 & 0.0139 & 0.0094 & 0.8278 & 0.0278 & 0.0270 \\
\hline \multirow{3}{*}{100} & $\alpha$ & 0.5032 & 0.0032 & 0.0022 & 0.5086 & 0.0086 & 0.0043 \\
\cline { 2 - 8 } & $\lambda$ & 0.4995 & -0.0005 & 0.0005 & 0.5026 & 0.0026 & 0.0011 \\
\cline { 2 - 8 } & $\theta$ & 0.5133 & 0.0133 & 0.0050 & 0.8149 & 0.0149 & 0.0121 \\
\hline
\end{tabular}


Continued of Table 1

\begin{tabular}{|c|c|c|c|c|c|c|c|}
\hline \multirow{2}{*}{$n$} & \multirow{2}{*}{ Par } & \multicolumn{3}{|c|}{ Set $3:(0.5,0.5,1.2)$} & \multicolumn{3}{|c|}{ Set $4:(0.8,0.5,0.5)$} \\
\hline & & MLE & Bais & MSE & MLE & Bais & MSE \\
\hline \multirow{3}{*}{30} & $\alpha$ & 0.5718 & 0.0718 & 0.2789 & 0.8199 & 0.0199 & 0.0215 \\
\hline & $\lambda$ & 0.5156 & 0.0156 & 0.0229 & 0.5026 & 0.0026 & 0.0022 \\
\hline & $\theta$ & 1.2751 & 0.0751 & 0.1121 & 0.5328 & 0.0328 & 0.0192 \\
\hline \multirow{3}{*}{50} & $\alpha$ & 0.5359 & 0.0359 & 0.0508 & 0.8182 & 0.0182 & 0.0130 \\
\hline & $\lambda$ & 0.5079 & 0.0079 & 0.0061 & 0.5030 & 0.0030 & 0.0013 \\
\hline & $\theta$ & 1.2448 & 0.0448 & 0.0606 & 0.5196 & 0.0196 & 0.0112 \\
\hline \multirow{3}{*}{100} & $\alpha$ & 0.5160 & 0.0160 & 0.0096 & 0.8082 & 0.0082 & 0.0061 \\
\hline & $\lambda$ & 0.5050 & 0.0050 & 0.0027 & 0.5023 & 0.0023 & 0.0006 \\
\hline & $\theta$ & 1.2240 & 0.0240 & 0.0277 & 0.5054 & 0.0054 & 0.0048 \\
\hline \multirow{2}{*}{$n$} & & \multicolumn{3}{|c|}{ Set $5:(1.5,0.5,0.5)$} & \multicolumn{3}{|c|}{ Set $6:(1.5,0.5,0.8)$} \\
\hline & Par & MLE & Bais & MSE & MLE & Bais & MSE \\
\hline \multirow{3}{*}{30} & $\alpha$ & 1.5453 & 0.0453 & 0.0780 & 1.5696 & 0.0696 & 0.1485 \\
\hline & $\lambda$ & 0.5063 & 0.0063 & 0.0029 & 0.5116 & 0.0116 & 0.0078 \\
\hline & $\theta$ & 0.5299 & 0.0299 & 0.0203 & 0.8451 & 0.0451 & 0.0464 \\
\hline \multirow{3}{*}{50} & $\alpha$ & 1.5205 & 0.0205 & 0.0452 & 1.5476 & 0.0476 & 0.0897 \\
\hline & $\lambda$ & 0.5016 & 0.0016 & 0.0016 & 0.5086 & 0.0086 & 0.0049 \\
\hline & $\theta$ & 0.5177 & 0.0177 & 0.0102 & 0.8290 & 0.0290 & 0.0266 \\
\hline \multirow{3}{*}{100} & $\alpha$ & 1.5187 & 0.0187 & 0.0212 & 1.5257 & 0.0257 & 0.0380 \\
\hline & $\lambda$ & 0.5021 & 0.0021 & 0.0008 & 0.5049 & 0.0049 & 0.0022 \\
\hline & $\theta$ & 0.5111 & 0.0111 & 0.0048 & 0.8161 & 0.0161 & 0.0133 \\
\hline
\end{tabular}

\section{Application}

In this section, we provide an application to a real data set to assess the flexibility of the OFrL model. In order to compare the OFrL model with other fitted distributions has four, five and six parameters. we compare the fits of the OFrL distribution with the beta generalized inverse Weibull geometric distribution (BGIWGc) (Elbatal et al., 2017), beta transmuted Weibull (BTW) (Afify et al., 2017), McDonald log-logistic (McLL) (Tahir et al., 2014), McDonald Weibull (McW) (Cordeiro et al., 2014), new modified Weibull (NMW) (Almalki and Yuan, 2013), transmuted complementary Weibull-geometric (TCWG) (Afify et al., 2014), beta Weibull (BW) (Lee et al., 2007) and exponentiated transmuted generalized Rayleigh (ETGR) (Afify et al., 2015) distributions.

The data set (Gross and Clark, 1975) on the relief times of twenty patients receiving an analgesic is 1.1, 1.4, 1.3, $1.7,1.9,1.8,1.6,2.2,1.7,2.7,4.1,1.8,1.5,1.2,1.4,3,1.7,2.3,1.6,2$.

The ML estimates along with their standard errors (SEs) of the model parameters are provided in Tables 2 and 3. In the same tables, the analytical measures including minus double log-likelihood (-2log L), Anderson Darling statistic (A*), Cramér-von Mises statistic ( $\left.\mathrm{W}^{*}\right)$, Akaike Information Criterion (AIC), corrected Akaike information criterion (CAIC), Bayesian information criterion (BIC) and Hannan-Quinn information criterion (HQIC) are presented.

Tables 2 list the MLEs of the model parameters and their corresponding standard whereas errors the values of 2LogL, AIC, CAIC, BIC, HQIC, $\mathrm{A}^{*}$ and $\mathrm{W}^{*}$ are given in Table 3. 
Table 2: MLEs and their SEs (in parentheses) for the data set.

\begin{tabular}{|c|c|c|c|c|c|c|}
\hline Model & \multicolumn{6}{|c|}{ MLE and SE } \\
\hline $\operatorname{OFrL}(\alpha, \theta, \lambda)$ & $\begin{array}{c}2.005 \\
(8.109)\end{array}$ & $\begin{array}{c}3.39 \\
(2.518)\end{array}$ & $\begin{array}{c}3.801 \\
(18.275)\end{array}$ & - & - & - \\
\hline BGIWGc $(\alpha, \gamma, \theta, p, a, b)$ & $\begin{array}{c}19.1874 \\
(33.03)\end{array}$ & $\begin{array}{l}20.5968 \\
(43.241)\end{array}$ & $\begin{array}{l}1.4346 \\
(0.837)\end{array}$ & $\begin{array}{l}9.8485 \\
(2.001)\end{array}$ & $\begin{array}{c}39.2308 \times 10^{-5} \\
(63.252)\end{array}$ & $\begin{array}{l}5.8015 \\
(4.346)\end{array}$ \\
\hline $\operatorname{BTW}(\alpha, \beta, a, b, \lambda)$ & $\begin{array}{l}5.6186 \\
(9.353)\end{array}$ & $\begin{array}{l}0.5311 \\
(0.148) \\
\end{array}$ & $\begin{array}{c}53.3438 \\
(111.453) \\
\end{array}$ & $\begin{array}{l}3.5683 \\
(4.265) \\
\end{array}$ & $\begin{array}{c}-0.7718 \\
(3.894) \\
\end{array}$ & - \\
\hline $\operatorname{McLL}(\alpha, \beta, a, b, c)$ & $\begin{array}{l}0.8811 \\
(0.109)\end{array}$ & $\begin{array}{l}2.0703 \\
(3.693)\end{array}$ & $\begin{array}{l}19.2254 \\
(22.341)\end{array}$ & $\begin{array}{l}32.0332 \\
(43.077)\end{array}$ & $\begin{array}{l}1.9263 \\
(5.165)\end{array}$ & - \\
\hline $\operatorname{McW}(\alpha, \beta, a, b, c)$ & $\begin{array}{c}2.7738 \\
(6.38)\end{array}$ & $\begin{array}{l}0.3802 \\
(0.188)\end{array}$ & $\begin{array}{c}79.108 \\
(119.131)\end{array}$ & $\begin{array}{l}17.8976 \\
(39.511)\end{array}$ & $\begin{array}{c}3.0063 \\
(13.968)\end{array}$ & - \\
\hline $\operatorname{NMW}(\alpha, \beta, \gamma, \delta, \theta)$ & $\begin{array}{l}0.1215 \\
(0.056)\end{array}$ & $\begin{array}{l}2.7837 \\
(20.37)\end{array}$ & $\begin{array}{c}8.227 \times 10^{-5} \\
\left(1.512 \times 10^{-3}\right)\end{array}$ & $\begin{array}{l}0.0003 \\
(0.025)\end{array}$ & $\begin{array}{l}2.7871 \\
(0.428)\end{array}$ & - \\
\hline $\operatorname{TCWG}(\alpha, \beta, \gamma, \lambda)$ & $\begin{array}{l}43.6627 \\
(45.459) \\
\end{array}$ & $\begin{array}{l}5.1271 \\
(0.814) \\
\end{array}$ & $\begin{array}{l}0.2823 \\
(0.042) \\
\end{array}$ & $\begin{array}{r}-0.2713 \\
(0.656) \\
\end{array}$ & - & - \\
\hline $\mathrm{BW}(\boldsymbol{\alpha}, \boldsymbol{\beta}, \mathbf{a}, \mathbf{b})$ & $\begin{array}{l}0.8314 \\
(0.954) \\
\end{array}$ & $\begin{array}{c}0.6126 \\
(0.34) \\
\end{array}$ & $\begin{array}{l}29.9468 \\
(40.413) \\
\end{array}$ & $\begin{array}{c}11.6319 \\
(21.9) \\
\end{array}$ & - & - \\
\hline $\operatorname{ETGR}(\alpha, \beta, \lambda, \delta)$ & $\begin{array}{l}0.1033 \\
(0.436) \\
\end{array}$ & $\begin{array}{l}0.6917 \\
(0.086)\end{array}$ & $\begin{array}{c}-0.342 \\
(1.971) \\
\end{array}$ & $\begin{array}{c}23.5392 \\
(105.371)\end{array}$ & - & - \\
\hline
\end{tabular}

Table 3: Measures of goodness-of-fit statistics for the data set

\begin{tabular}{|c|c|c|c|c|c|c|c|}
\hline Model & $-2 \log \mathbf{L}$ & AIC & CAIC & BIC & HQIC & \multirow{2}{*}{$\mathbf{A}^{*}$} & $\mathbf{W}^{*}$ \\
\hline OFrL & 30.781 & 36.781 & 38.281 & 34.685 & 37.365 & 0.1717 & 0.03137 \\
\hline BGIWGc & 31.662 & 43.662 & 50.124 & 39.468 & 44.828 & 0.24665 & 0.0434 \\
\hline BTW & 33.051 & 43.051 & 47.337 & 39.556 & 44.023 & 0.39769 & 0.06896 \\
\hline McLL & 33.854 & 43.854 & 48.14 & 40.359 & 44.826 & 0.46199 & 0.07904 \\
\hline McW & 33.907 & 43.907 & 48.193 & 40.412 & 44.879 & 0.46927 & 0.08021 \\
\hline NMW & 41.173 & 51.173 & 55.459 & 47.678 & 52.145 & 1.0678 & 0.17585 \\
\hline TCWG & 33.607 & 41.607 & 44.274 & 38.811 & 42.385 & 0.43603 & 0.07252 \\
\hline BW & 34.396 & 42.396 & 45.063 & 39.6 & 43.174 & 0.51316 & 0.0873 \\
\hline ETGR & 36.856 & 44.856 & 47.523 & 42.06 & 45.634 & 0.79291 & 0.13629 \\
\hline
\end{tabular}

Table 3 compares the fits of the OFrL distribution with the BGIWGc, BTW, McLL, McW, NMW, TCWG, BW and ETGR distributions. The figures in these tables show that the OFrL model has the lowest values for -2LogL, AIC, CAIC, HQIC, $\mathrm{A}^{*}$ and $\mathrm{W}^{*}$ among all fitted distributions. So, it could be chosen as the best model. The fitted pdf and pp plots for the OFrL model are displayed in Figure 2. Figure 3 shows the estimated cdf and sf for the OFrL model. From these plots it is evident that the new model provides close fit to the data. 

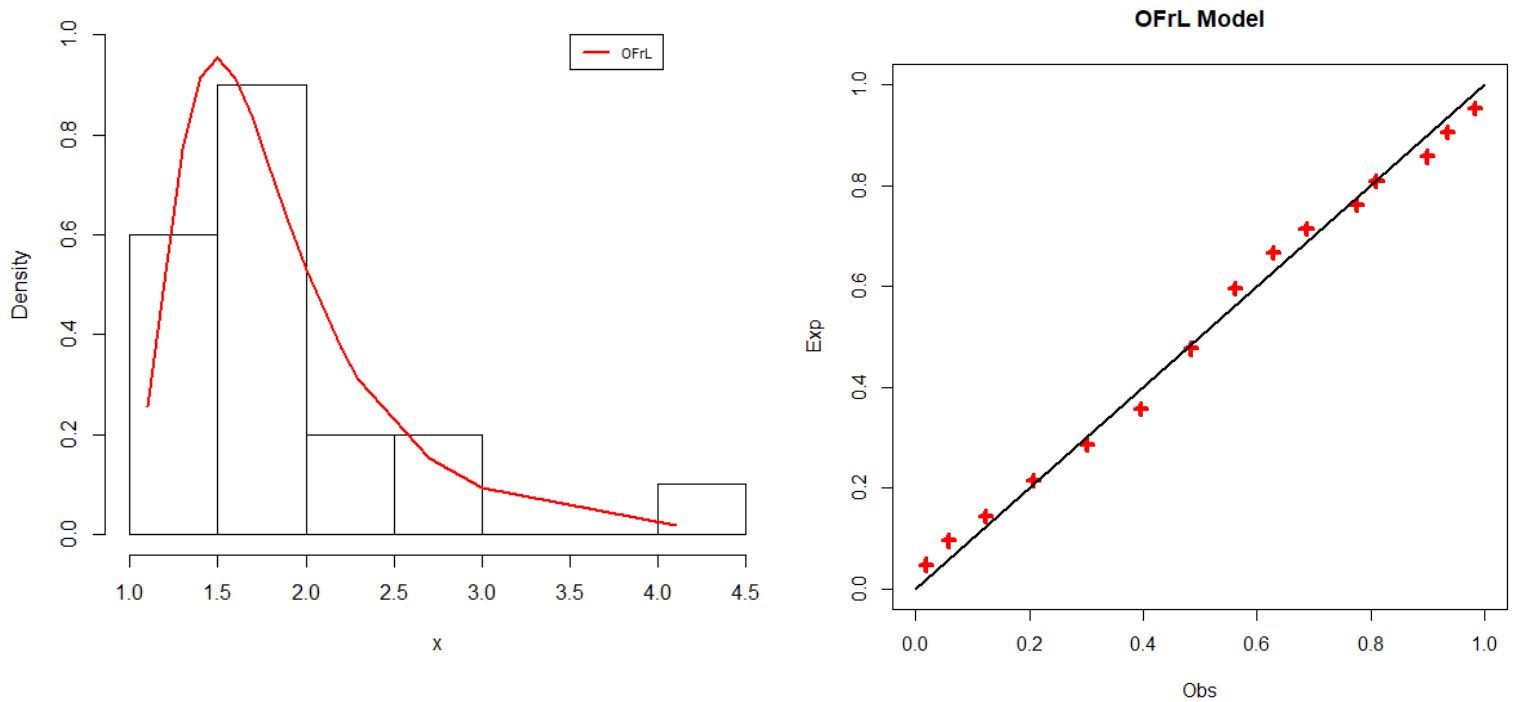

Figure 2: The empirical pdf and pp plots of the OFrL model
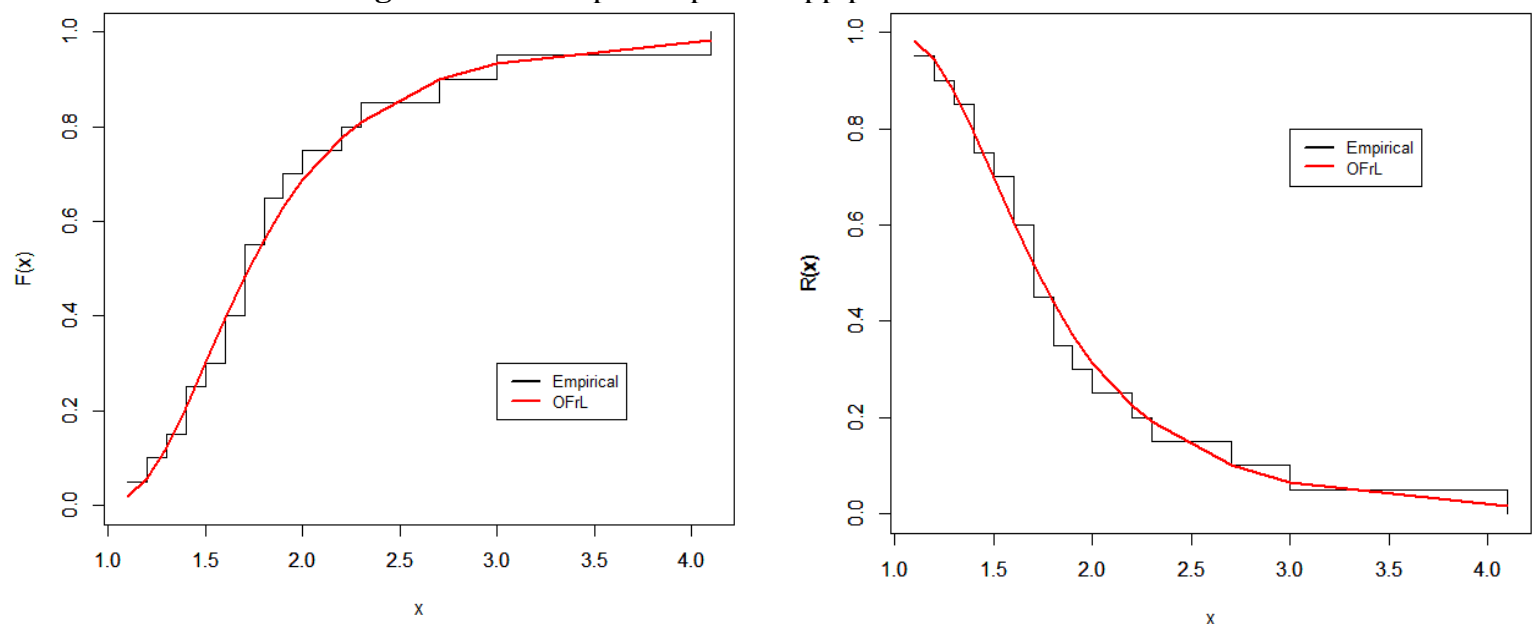

Figure 3: The empirical cdf and sf of the OFrL model

\section{Summary}

In this paper, we study a three-parameter distribution, called the odd Frèchet Lomax (OFrL) distribution. The OFrL pdf can be expressed as a mixture of $\mathrm{L}$ densities. We derive explicit expressions for the quantile function, moments, moment generating function, probability weighted moments, and order statistics. The ML estimation method is used to estimate the model parameters. We provide some numerical results to assess the performance of the proposed model. The practical importance of the OFrL distribution is demonstrated by means of one real data set.

\section{References}

Abdul-Moniem, I. B. and Abdel-Hameed, H. F. (2012). On exponentiated Lomax distribution, International Journal of Mathematical Archive 3, 2144-2150.

Afify, A. Z., Nofal, Z. M. and Butt, N. S. Transmuted complementary Weibull geometric distribution. Pakistan Journal of Statistics and Operations Research, 10, (2014), 435-454.

Afify, A. Z., Nofal, Z. M. and Ebraheim, A. N. Exponentiated transmuted generalized Rayleigh distribution: A new four parameter Rayleigh distribution. Pakistan Journal of Statistics and Operations Research, 11, (2015), 115 134. 
Afify A. Z., Yousof, H. M. and Nadarajah, S. The beta transmuted-H family for lifetime data. Statistics and Its Interface, 10, (2017), 505-520.

Almalki, S. J. and Yuan, J. A new modified Weibull distribution. Reliability Engineering and System Safety, 111, (2013), 164-170.

Corbellini, A., Crosato, L., Ganugi, P. and Mazzoli, M. (2007). Fitting Pareto II distributions on firm size: Statistical methodology and economic puzzles. Paper presented at the International Conference on Applied Stochastic Models and Data Analysis, Chania, Crete.

Cordeiro, G. M., Hashimoto, E. M. and Ortega, E. M. M. The McDonald Weibull model. Statistics, 48, (2014), $256-278$

Cordeiro, G.M., Ortega, E.M. and Popovi 'c, B. z. (2013). The gamma Lomax distribution. Journal of Statistical Computation and Simulation, 85(2), 305-319.

Elbatal, I., El Gebaly, Y. M. and Amin, E. A. The beta generalized inverse Weibull geometric distribution and its applications. Pakistan journal of statistics and operation research, 13(1), (2017), 75-90.

El-Bassiouny, A. H., Abdo, N. F. and Shahen, H. S. (2015). Exponential lomax distribution, International Journal of Computer Applications, 121(13), 24-29.

Ghitany, M.E., Al-Awadhi, F. A. and Alkhalfan, L. A. (2007). Marshall Olkin extended Lomax distribution and its application to censored data. Communications in Statistics-Theory and Methods, 36, 1855-1866.

Gross, A. J. and Clark, V. A. Survival distributions: Reliability applications in the biomedical sciences. John Wiley and Sons, New York, (1975).

Haq, M. and Elgarhy, M. The odd Frèchet-G family of probability distributions. Journal of Statistics Applications \& Probability, 7, (2018), 185-201.

Hassan, A.S. and Al-Ghamdi, A.S. (2009). Optimum step stress accelerated life testing for Lomax distribution. Journal of Applied Sciences Research, 5, 2153-2164.

Kilany, N. M. (2016). Weighted Lomax distribution. Springer Plus, 5(1), article no. 1862.

Lee, C., Famoye, F. and Olumolade, O. Beta-Weibull distribution: Some properties and applications to censored data. Journal of Modern Applied Statistical Methods, 6, (2007), 173-186.

Lemonte, A. J. and Cordeiro, G. M. (2013). An extended Lomax distribution. Statistics, 47(4), 800 -816.

Lomax, K. S. (1954). Business failures: Another example of the analysis of failure data, Journal of the American Statistical Association, 49, 847-852.

Tahir, M. H., Cordeiro, G. M., Mansoor, M. and Zubair, M. (2015). The Weibull-Lomax distribution: properties and applications. Hacettepe Journal of Mathematics and Statistics, 44(2), 461-480.

Tahir, M. H., Mansoor, M., Zubair, M. and Hamedani, G. McDonald log logistic distribution with an application to breast cancer data. Journal of Statistical Theory and Applications, 13, (2014), 65-82. 